\title{
$\nabla$ Bio Ceramics: A Modern Approach to Cementsin Endodontics
}

IJCRR
Section: Healthcare
ISI Impact Factor
(2019-20): 1.628
IC Value (2019): 90.81
SJIF (2020) = 7.893
Cc) (1) (3)
Copyright@IJCRR

\section{Kajol Relan ${ }^{1 *}$, Manoj Chandak², Pradnya Nikhade ${ }^{3}$, Pooja Chandak ${ }^{1}$}

'Postgraduate student, Department of Conservative Dentistry and Endodontics, Sharad Pawar Dental College, DMIMS, Wardha -442001, India; 'Professor, Department of Conservative Dentistry and Endodontics, Sharad Pawar Dental College, DMIMS, Wardha -442001, India; ${ }^{3}$ HOD, Department of Conservative Dentistry and Endodontics, Sharad Pawar Dental College, DMIMS, Wardha -442001, India.

\section{ABSTRACT}

There is an exponential growth in Endodontics due to various advances in materials used in Endodontics. Bioglass was a new material introduced in dentistry. Among them are Bioceramics that are biocompatible. They include 'alumina and zirconia, bioactive glass, glass ceramics, coatings and composites, Hydroxyapatite and resorbable calcium phosphate'. Bioceramic types of cement can be widely used for dentinal tubule closure. The voids between the dentinal walls and obturating material can be homogenously sealed by bioceramics. Bio ceramics have bioactivity that helps bone repair and neoformation due to their interaction with periapical tissues. Thorough knowledge of newer bioceramic materials is necessary to ensure the appropriate selection of material according to the clinical situation. The objective of this article is to review the various bioceramic materials and to choose the appropriate material for successful endodontic treatment.

Key Words: Bioceramics, Bioglass, Bio dentin, Calcium silicate-based types of cement, Calcium phosphate-based types of cement

\section{INTRODUCTION}

There is an exponential growth in Endodontics due to various advances in materials used in Endodontics. Bioglass was a new material introduced by L.L Hench and others in 1969. Various Glasses and Ceramics can bond to living bone was also observed by them. ${ }^{1}$ Earlier Calcium hydroxide was used. Calcium hydroxide is used in various pulp therapies. It is used as a pulp covering agent, in apexification, as an endodontic sealer, perforation repair material. ${ }^{2}$ The inorganic, non-metallic materials prepared by heating raw minerals at high temperatures are the Ceramics. Among them are the Bioceramics that are biocompatible. ${ }^{1}$ The brilliant biocompatibility is due to the resemblance to the biological procedure of forming Hydroxyapatite. This is also due to the ability to induce Regenerative response from periapical tissues. ${ }^{3}$ Bio ceramics are osteoinductive materials. During the bone healing process, after coming in contact they absorb osteoinductive materials. Currently, bone graft materials are used in extraction socket healing. This is because these materials are inert and also can induce healing. ${ }^{4}$ They include 'alumina and zirconia, bioactive glass, glass ceramics, coatings and composites, Hydroxyapatite and resorbable calcium phosphate'.
MTA became popular in Endodontics as the first generation bioceramic cement. There is the prevention of bacterial adhesion as bioceramics form porous powders that contain nanocrystals that having a diameter of 1-3 nm. ${ }^{5}$ Bioceramic cement can be widely used for dentinal tubule closure. The voids between the dentinal walls and obturating material can be homogenously sealed by bioceramics. Bioceramics have bioactivity that helps bone repair and neoformation due to their interaction with periapical tissues.

\section{CLASSIFICATION}

Bioceramics can be classified as ${ }^{6,7}$

1. Bioinert: These materials do not interact with biological systems. eg: Alumina, Zirconium.

2. Bioactive: These are tough tissues that are able of undergoing interfacial communications with the surrounding tissue. eg: 'Bioactive glass, Hydroxyapatite, Bioactive glass ceramics, calcium silicates'.

3. Biodegradable: They are soluble/ Resorbable. They are ultimately replaced or incorporated into the tissue. eg: Tricalcium phosphate, Bioactive glass.

\section{Corresponding Author:}

Dr. Kajol Relan, Postgraduate Student, Department of Conservative Dentistry and Endodontics, Sharad Pawar Dental College, DMIMS, Wardha -442001; Phone: 8830546552; Email: kajolrelan10@gmail.com

ISSN: 2231-2196 (Print)

Received: 08.09 .2020

\section{ISSN: 0975-5241 (Online)}

Revised: 12.11 .2020
Accepted: 04.01 .2021
Published: 19.05 .2021 


\section{BIOCERAMICS IN ENDODONTICS}

1. Calcium Silicate based:

Types of cement:

- Portland Cement

- Mineral Trioxide Aggregate (MTA).

- Biodentin

Sealers :

- Endo CPM Sealer

- MTA Fillapex

- BioRoot RCS

- TechBiosealer

1. Calcium Phosphate/ Tricalcium Phosphate/ Hydroxyapatite based

2. The mixture of Calcium silicates and Calcium phosphates

- iRoot BP

- iRoot BP Plus

- iRoot FS

- Endosequence BC sealer

- Bioaggregate

- Tech Biosealer

- Ceramicrete

\section{PROPERTIES OF BIOCERAMICS 8,9}

Bio ceramics have excellent biocompatibility and is non-toxic. They do not shrink upon setting they expand a little after completion of setting. They do not produce any significant inflammatory response when used during obturation and in root repair. They form a chemical bond amid dentin and filling materials and form hydroxyapatite. They have a high $\mathrm{pH}$ (12.8) during the start of $24 \mathrm{hrs}$ of setting. They are powerfully antibacterial, have hydrophilic nature, have outstanding sealing ability, sets fast ( 3 to $4 \mathrm{hrs}$ ), small particle size, easy to use. They have excellent physical properties and it has improved convenience and delivery method.

\section{CALCIUM SILICATE BASED BIO CERAMICS}

\section{Portland Cement}

Joseph Aspdin, in 1824 introduced a material Portland cement (PC) and patented it. It was obtained from a calcining mixture of limestones from Portland in England and silicon argillaceous materials. ${ }^{10}$ It is an easily available material and cheap. As MTA, it is available as grey and white. ${ }^{11}$

Discolouration: Grey PC shows discolouration compared to white PC.

Solubility: PC showed little solubility and improved washout resistance comparing to MTA.

Bioactivity: PC showed lesser bioactivity as compared to MTA. Calcium ion release and hydroxyapatite crystal formation are there with grey as well as white PC.
Antibacterial properties:- PC has powerful action against bacteria and fungi against E. faecalis, Micrococcus luteus, Staph aureus, staph epidermidis, Pseudomonas aeruginosa, Candida albicans. ${ }^{12}$

Sealing ability: As perforation repair material, when checked by protein leakage method, white PC has better sealing when compared to white and grey MTA.

Limitations: PC releases a high quantity of lead and arsenic, hence the safety of PC is questionable. The seal of restoration can be jeopardized because of its high solubility. Crack formation in the tooth occurs due to excessive setting expansion.

\section{Mineral trioxide aggregate (MTA)}

MTA had been the 1st bioceramic material effectively used in endodontics. It was introduced by Dr. Mahmoud Torabinejad in 1993. The development of this cement was founded on Portland cement, in Loma Linda University - California. It has osteoconductive, osteoinductive, and biocompatible properties. MTA was used as 'retrograde filling material and perforation closing'. The material contents, physical and chemical properties of PC and MTA are comparable. Portland cement, contains 'Tricalcium silicate (3CaO-SiO2), dicalcium silicate (2CaO $\cdot \mathrm{SiO} 2)$, tricalcium aluminate $(3 \mathrm{CaO} \cdot \mathrm{Al} 2 \mathrm{O} 3)$ and calcium sulfate $(2 \mathrm{CaSO} 4 \cdot \mathrm{H} 2 \mathrm{O})^{\prime}$. MTA is adding has bismuth oxide - it is a nonsoluble substance to give the material radiopacity. MTA - a calcium silicate cement has 'tricalcium silicate, dicalcium silicate, and tricalcium aluminate'. Material has two forms - grey and white. Grey coloured MTA was available up to 2002. In the same year, WMTA was presented as ProRoot MTA. This was introduced to overcome the disadvantage of discolouration caused by GMTA. ${ }^{11}$

\section{Properties of MTA}

Compressive strength: It is $\sim 40 \mathrm{MPa}$ in $24 \mathrm{hrs}$ and $\sim 67$ MPa in 21 days.

Setting reaction: The setting reaction of MTA is exothermic. It requires hydration of the powder resulting in a paste that matures over time. The Tricalcium silicate and dicalcium silicate reacting with water and producing calcium silicate hydrates $(\mathrm{C}-\mathrm{S}-\mathrm{H})$ and calcium hydroxide $[\mathrm{Ca}(\mathrm{OH}) 2]$.

$2[3 \mathrm{CaO} . \mathrm{SiO} 2]+6 \mathrm{H} 2 \mathrm{O}---->3 \mathrm{CaO} \cdot 2 \mathrm{SiO} 2.3 \mathrm{H} 2 \mathrm{O}+3 \mathrm{Ca}(\mathrm{OH}) 2$ $2[2 \mathrm{CaO} . \mathrm{SiO} 2]+4 \mathrm{H} 2 \mathrm{O}---->3 \mathrm{CaO} .2 \mathrm{SiO} 2.3 \mathrm{H} 2 \mathrm{O}+\mathrm{Ca}(\mathrm{OH}) 2$

$7 \mathrm{Ca}(\mathrm{OH}) 2+3 \mathrm{Ca}(\mathrm{H} 2 \mathrm{PO} 4) 2---->\mathrm{Ca} 10(\mathrm{PO} 4) 6(\mathrm{OH}) 2+$ $12 \mathrm{H} 2 \mathrm{O}$

Accelerator in setting is Calcium chloride. Retarder in setting is Sodium hypochlorite. these affect the formation of calcium hydroxide. ${ }^{13}$

Setting time: The powder liquid ratio for MTA is $3: 1$. As noted by Torabinejad et al, the setting time of grey ProRoot 
MTA is $2 \mathrm{hrs} 45 \mathrm{~min}$. As noted by Islam et al the setting time for White MTA is 2 hrs $20 \mathrm{~min}$ and for grey, MTA is $2 \mathrm{hrs}$ 55 min. ${ }^{11}$

pH: Initial $\mathrm{pH}$ of hydrated MTA is 10.2. The $\mathrm{pH} 3 \mathrm{hrs}$ after mixing rises up to 12.5 .

Pushout bond strength and Flexural strength: Push-out bond strength of MTA as noted by Aggarwal V et al. After 24 hours is $\sim 5.2 \pm 0.4 \mathrm{MPa}$. After 7 days, the set cement had a strength that increased to $9.0 \pm 0.9 \mathrm{MPa}^{14}$. After placing moist cotton pellet on the MTA during setting for $24 \mathrm{hrs}$, Walker et al noted increased flexural strength as $\sim 14.27 \pm 1.96 \mathrm{MPa} .{ }^{15}$

Porosity and Microhardness: The porosity depends on the amount of water added for paste, bubble entrapment, or $\mathrm{pH}$ value. MTA microhardness is affected adversely by low $\mathrm{pH}$, less humidity, more condensation pressure.

Sealing ability, Particle size, and Biocompatibility: MTA materials have low microleakage compared to traditional materials while using as an apical restoration and when $3 \mathrm{~mm}$ of MTA remained after root-end resection. Reducing the thickness of MTA causes microleakage. The particle size of MTA affects the handling characteristics of MTA. Small particle size increases the contact with the liquid. This results in increased early strength and ease of handling. Grey MTA has a larger particle size than white MTA. MTA is not mutagenic, is not neurotoxic, and does not produce side effects on microcirculation. MTA also has an anti-inflammatory effect on pulp. MTA also has osteoconductive, cementoconductive, cementoinductive effects.

\section{Advantages:}

- Calcium hydroxide is in such a way which gives calcium ions for cell attachment and proliferation.

- High $\mathrm{pH}$ affects bacteria.

- Cytokine production modulation.

- Hard tissue migration and differentiation occur.

- Provides biological seal by forming hydroxyapatite on MTA surface.

\section{Limitations:}

- Prolonged sitting time.

- High cost and difficulty in handling.

- No known solvent is there for the material.

- Once placed it is difficult to remove.

\section{Biodentin}

Biodentin was commercially available in 2009 ( Septodont, Saint Maur des Fosses, France). It is based on calcium silicate cement. Biodentin is prepared using MTA based technology with better physical and handling properties than MTA. Biodentin is fast setting than MTA hence reduces bacterial contamination.

\section{Properties of Biodentin}

Setting reaction: Setting reaction is the same as MTA that results in the formation of Calcium silicate hydrogel (C-S$\mathrm{H})$ and $\mathrm{Ca}(\mathrm{OH})_{2}$. The nucleation site for calcium silicate hydrogel is provided by Calcium carbonate. Hence the induction period is reduced and it causes the cement to set fast, It also improves the microstructure. The polymer formed is hydrosoluble that improves handling and there is a reduction in viscosity of cement. ${ }^{16}$

Setting time: Biodentin has a working time of 6 minutes. Its start setting time is 9-12 minutes and the completed setting time is 45 minutes. By adding Calcium chloride the setting time of biodentin is accelerated. ${ }^{16}$

Compressive strength and elastic modulus: Compressive strength reaches up to $100 \mathrm{MPa}$ in 1st hour. The strength keeps on increasing up to $200 \mathrm{MPa}$ at $24 \mathrm{hrs}$. This value is more than that for the Glass ionomer cement. The strength reaches $300 \mathrm{MPa}$ after 1 month. At this time the value stabilizes that is comparable to natural dentin ( $297 \mathrm{MPa}$ ). The Elastic Modulus of Biodentin is $22 \mathrm{GPa}$ that is similar to dentin which is $18.5 \mathrm{GPa} .{ }^{16}$

Pushout bond strength and Flexural strength: Biodentin has more pushout bond strength than MTA at $24 \mathrm{hrs}$. Contamination with bleeding does not affect the pushout bond strength whereas it does in the case of MTA. The flexural strength of Biodentin after $2 \mathrm{hrs}$ was $34 \mathrm{MPa} .{ }^{16}$

Microhardness and sealing ability: Microhardness of Biodentin was $51 \mathrm{VHN}$ after $2 \mathrm{hrs}$. The value reached $69 \mathrm{VHN}$ after 1 month. Natural dentin has a hardness value of 60-90 VHN. Biodentin creates a stable anchorage along with bacteria tight effect. ${ }^{16}$

Antibacterial activity, pH, and Biocompatibility: $\mathrm{pH}$ of Biodentin is 12.5 that is bacteriostatic, and disinfect the dentin. Biodentin has no toxic and adverse effects on cell function. TGF - B1 ( growth factor) is secreted from pulp cells due to biodentin. This causes angiogenesis, progenitor cell recruitment, cell differentiation, and mineralization. ${ }^{16}$

\section{Endo CPM sealer (EGO SRL, Buenos Aires, Ar- gentina)}

It is an MTA based calcium silicate cement. It has the same or improved physical, chemical, and biological properties compared to MTA. It has the same composition as that of MTA, calcium carbonate is added for reducing the $\mathrm{pH}$ to 10 of the complete set cement. This limits the surface necrosis of the nearby tissue and allows the alkaline phosphatase action. It has 'satisfactory radiopacity, hydroxyl and calcium ion release, antibacterial activity, biocompatibility ( stimulation of mineralization), no cytotoxicity'. However, the microleakage of the sealer is more than that of MTA. ${ }^{11}$ 


\section{MTA Fillapex (Angelus, Brazil)}

It is an MTA based salicylate resin root canal sealer. It contains $13.2 \%$ MTA. It has a higher radiopacity. It releases calcium ions that help in bone healing and tissue regeneration. It has a higher flow and low film thickness. This helps easy penetration into the lateral and accessory canals. It can be simply removed if retreatment is essential. It has less solubility hence outstanding seal inside the canal is maintained. ${ }^{17}$

\section{EXPERIMENTAL CALCIUM ALUMINO- SILICATES}

EndoBinder (Binderware, São Carlos, SP, Brazil): It is a new calcium aluminate based endodontic cement. It is produced by conserving the properties and clinical applications of MTA and elimination of traces of 'Magnesium oxide $(\mathrm{MgO})$, and Calcium oxide $(\mathrm{CaO})$ and ferric oxide $(\mathrm{FeO})$ '. These elements result in the expansion of material that is not desired. Ferric oxide (FeO) is accountable for discolouration. ${ }^{17}$

Generex A (Dentsply Tulsa Dental Specialties, Tulsa, OK, USA): It is based on calcium silicate material. It has little resemblances to ProRoot MTA but is mixed with unique gels in place of water that is used for MTA. However, it is difficult in handling as compared to MTA. It is used mostly for perforation repair and retrograde fillings. ${ }^{17}$

Capasio (Primus Consulting, Bradenton, FL, USA): It is made up of 'bismuth oxide, dental glass and calcium alumino-silicate with a silica and polyvinyl acetate-based gel'. Capasio as well as MTA promoted apatite deposition after exposing it to synthetic tissue fluid hence can be concluded that it has mineralizing property. It can penetrate dentinal tubules when used as root-end filling material. ${ }^{17}$

Calcium Phosphate based Ceramics: They were developed by Hench in 1971. He developed Bioglass that was a $\mathrm{Ca}$ and $\mathrm{P}$ containing glass-ceramic. He also showed that it bonded chemically with host bone via a $\mathrm{CaP}$ rich layer. ${ }^{17}$

Compressive strength: For porous ceramics, it was 30-170 $\mathrm{MPa}$. For dense ceramics, it was 120-917 MPa.

\section{Uses:}

- Bone substitute.

- Bone graft material.

- Pulp capping materials.

- Active restorative materials with ACP as filler

\section{Limitations:}

- less strength.

- caused fatigue fracture.

- failure in load-bearing situations.

\section{MIXTURE OF CALCIUM SILICATES AND CAL- CIUM PHOSPHATES}

Bio aggregate (Verio Dental Co. Ltd., Vancouver, Canada): Biaggregate is made up of nanoparticles of 'tricalcium silicate, calcium phosphate, silicon dioxide. This shows increased performance than MTA. Tantalum oxide is added that acts as a radiopacifier and it does not contain aluminium. Tricalcium silicate is the main component. Bioaggregate has no aluminium and contains additives like 'calcium oxide and silicon dioxide. It has greater calcium release as compared to MTA. It is more biocompatible, has a better sealing ability, higher fracture resistance, and acid resistance than MTA. It has a better ability for inducing odontoblastic differentiation and mineralization than MTA in pulp capping. ${ }^{11}$

Setting reaction: Calcium silicate hydrate and calcium oxide are produced by the hydration of tricalcium silicate. 'Calcium silicate hydrate' gets deposited around cement grains. Calcium oxide is reacted with silicon dioxide and forms extra calcium silicate hydrate. Hence calcium hydroxide is reduced in aged cement. While in MTA angelus, no additions were done but still, calcium hydroxide was present in aged cement. ${ }^{18}$

Endosequence BC sealer [Brasseler USA]: It is not soluble, radiopaque, and aluminium free material. It is based on calcium silicate cement. It has 'Zirconium oxide, calcium silicates, calcium phosphate monobasic, calcium hydroxide, filler, and thickening agents. It requires the presence of water to set and harden. ${ }^{18}$

Setting reaction : The hydration reaction of calcium silicates is as follows

$2\left[3 \mathrm{CaO}-\mathrm{SiO}_{2}\right]+6 \mathrm{H}_{2} \mathrm{O} \rightarrow 3 \mathrm{CaO}_{2} \mathrm{SiO}_{2}-3 \mathrm{H}_{2} \mathrm{O}+3 \mathrm{Ca}(\mathrm{OH})_{2}$ $2\left[2 \mathrm{CaO}-\mathrm{SiO}_{2}\right]+4 \mathrm{H}_{2} \mathrm{O} \rightarrow 3 \mathrm{CaO}_{2} \mathrm{SiO}_{2}-3 \mathrm{H}_{2} \mathrm{O}+\mathrm{Ca}(\mathrm{OH})_{2}$

The precipitation reaction $(\mathrm{C})$ of calcium phosphate apatite is as follows:

$7 \mathrm{Ca}(\mathrm{OH}) 2+3 \mathrm{Ca}\left(\mathrm{H}_{2} \mathrm{PO}_{4}\right) 2 \rightarrow \mathrm{Ca} 10\left(\mathrm{PO}_{2}\right) 6(\mathrm{OH})_{2}+12 \mathrm{H}_{2} \mathrm{O}$

No mixing is required and can be applied straight into the root canal. The working time can be more than $4 \mathrm{hrs}$ at room temperature. However, in very dry root canals, it can be greater than $10 \mathrm{hrs}^{18}$

\section{EndoSequence Root Repair Material/IrootSP/ IrootBP (ERRM; Brasseler, Savannah, GA)}

It mainly consists of "calcium silicate, monobasic calcium phosphate, zirconium oxide, tantalum oxide, and filler agents'. Paste form is marketed in already loaded syringes. Also marketed in a putty form that can be moulded. The time of working for cement is $30 \mathrm{~min}$. The reaction starts in presence of moisture. The final set is achieved after $4 \mathrm{hrs}$. However, it has a lesser sealing ability than MTA. The antibacte- 
rial property of this cement is similar to that of MTA. ERRM has no cytotoxic effect. ${ }^{18}$ As compared to MTA and Biodentin, ERRM is considered to have superior sealing ability for furcation repair. ${ }^{19}$

\section{Endodontic and Restorative uses of Bioceramics}

- Bio ceramics are used as sealers along with Guttapercha.

- They are effective as pulp capping agents and dentin substitute.

- They can be used during apexification and regenerative endodontics.

- They are used as a retrograde filling material and repairing perforation.

- They can be used as a canal locator owing to their excellent flowability and radiopacity.

- They can be used in resorption.

- They can be used in dentin hypersensitivity and dentin remineralization.

\section{CONCLUSION}

Bio ceramics are not currently used materials for endodontic use. They present various advantages as compared to conventional cement. Bio ceramics have a wide range of applications in restorative dentistry and endodontics. Thorough knowledge of newer bioceramic materials is necessary to ensure the appropriate selection of material according to the clinical situation. The tricalcium silicate-based materials have various biological advantages and have increasing use in endodontic therapy in the future.

Conflict of Interest:- None

Acknowledgement:- Authors would like to thank Dr Nikhil Mankar for his valuable support.

Funding support:- Nil.

\section{REFERENCES}

1. Hench LL. The story of bioglass. J Mater Sci Mater Med. 2006; 17: 967-978.

2. Chandak MG, Modi RR, Rathi BJ, Gogiya RJ, Bhutada P. In vitro comparative assessment of diffusion of ion from calcium hydroxide with three different phytomedicine pastes through dentin. Wor J Dent 2018; 9(5):377-371.
3. Damas BA, Wheater MA, Bringas JS, Hoen MM.Cytotoxicity comparison of mineral trioxide aggregates and EndoSequence bioceramic root repair materials. J Endod 2011;37:372-375.

4. Shilpa BS, Dhadse PV, Bhongade ML, Puri K, Nandanwar J. Evaluation of the effectiveness of platelet-rich fibrin for ridge preservation after atraumatic extraction. Adv Dent Res 2017:4:294-300.

5. Hermansson L. Nanostructural bioceramics: Advances in Chemically Bonded Bioceramics. CRC Press 2014.

6. Best SM, Porter AE, Thian ES, Huang J. Bioceramics: Past, present and for the future. J Eur Ceram Soc 2008;23:1319-1327.

7. Hickman K. Bioceramics. Internet (Overview) April 1999. http://www.csa.com/discoveryguides/archives/bceramics.php.

8. Prati C, Gandolfi MG. Calcium silicate bioactive cement: Biological perspectives and clinical applications. Dent Mater 2015;31(4):351-370.

9. Utneja S, Nawal RR, Talwar S, Verma M. Current perspectives of bio-ceramic technology in endodontics: Calcium enriched mixture cement - review of its composition, properties and applications. Restore Dent Endod 2015;40(1):1-13.

10. Viola NV, Tanomaru Filho M, Cerri PS. MTA versus portland cement: Review of the literature. Rev Sul-bras Odontol 2011;8(4):446-452.

11. Parirokh M, Torabinejad M. Calcium silicate-based cements in mineral trioxide aggregate: Properties and clinical applications. Hoboken, NJ, USA: John Wiley \& Sons, 2014.

12. Parirokh M, Torabinejad M. Mineral trioxide aggregate: A comprehensive literature review--part i: Chemical, physical, and antibacterial properties. J Endod 2010;36(1):16-27.

13. Roberts HW, Toth JM, Berzins DW, Charlton DG. Mineral trioxide aggregate material use in endodontic treatment: A review of the literature. Dent Mater 2008;24(2):149-164.

14. Aggarwal V, Singla M, Miglani S, Kohli S. Comparative evaluation of push-out bond strength of proroot mta, biodentine, and mta plus in furcation perforation repair. J Conserv Dent 2013;16(5):462465.

15. Walker MP, Diliberto A, Lee C. Effect of setting conditions on mineral trioxide aggregate flexural strength. J Endod 2006;32(4):334-336.

16. Malkondu O, Karapinar Kazandag M, Kazazoglu E. A review on biodentine, a contemporary dentine replacement and repair material. Biomed Res Int 2014;2014:160951.

17. Saxena P, Gupta SK, Newaskar V. Biocompatibility of rootend filling materials: Recent update. Restore Dent Endod 2013;38(3):119-127.

18. LeGeros RZ. Calcium phosphate materials in restorative dentistry: A review. Adv Dent Res 1988;2(1):164-180.

19. Duraivel D, Fayeez A, Poorni S, Diana D, Srinivasan MR. Management of Non-Vital Teeth with Open Apex Using Endosequence Root Repair Material, Mineral Trioxide Aggregate and Biodentin-A Case Series. Int J Curr Res Rev 2017;9(22):26. 